\title{
Correction: Preeclampsia predicts higher incidence of bronchopulmonary dysplasia
}

\section{Gustavo Rocha ${ }^{1}$ Filipa Flor de Lima ${ }^{1,2}$ - Ana Paula Machado ${ }^{3}$ Hercília Guimarães ${ }^{1,2}$. Collaborators of the Hypertensive Disorders of Pregnancy Study Group}

Published online: 3 August 2018

(c) Nature America, Inc., part of Springer Nature 2018

Correction to: Journal of Perinatology; https://doi.org/10. 1038/s41372-018-0133-8; published online 29 May 2018

The original version of the Article omitted the Collaborators of the Hypertensive Disorders of Pregnancy Study
Group from the author list. This has now been corrected in both the PDF and HTML versions of the Article.

Gustavo Rocha

gusrocha@sapo.pt

1 Department of Neonatology, Centro Hospitalar São João,

Porto, Portugal

2 Faculty of Medicine, University of Porto, Porto, Portugal

3 Department of Obstetrics and Gynaecology, Centro Hospitalar São João, Porto, Portugal 